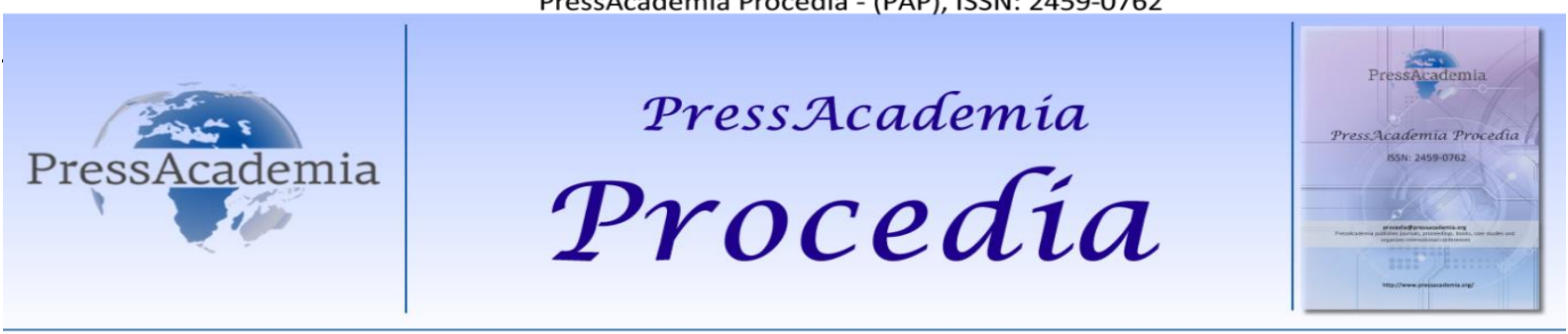

Global Business Research Congress (GBRC), May 24-25, 2017, Istanbul, Turkey.

\title{
MACROECONOMIC FACTORS AFFECTING THE COUNTRY CREDIT INVESTIGATIONS: AN APPLICATION ON FRAGILE EIGHT
}

DOI: 10.17261/Pressacademia.2017.404

PAP-GBRC-V.3-2017(19)-p.197-205

\section{Salih Arslan}

Dumlupınar Üniversitesi Uygulamalı Bilimler Yüksekokulu, Kütahya, Türkiye saliharslandpu@hotmail.com

To cite this document

Arslan, S., A.,E. and S. Arslan (2017). Macroeconomıc factors affecting the country credit investigations: an application on fragile eight PressAcademia Procedia (PAP), V.3, p.197-205

Permemant link to this document: http://doi.org/10.17261/Pressacademia.2017.404

Copyright: Published by PressAcademia and limited licenced re-use rights only.

\begin{abstract}
This study examines the relationship between macroeconomic variables and country credit ratings determined by credit rating agencies. In this context, the credit ratings of the countries (Turkey, Brazil, Chile, Argentina, India, Indonesia, Russia, and S. Africa), which are called Fragile Sekizli, are ranked by Fitch, one of the three major credit rating agencies. At the same time, country credit ratings are used as a dependent variable, independent of macroeconomic factors affecting country credit ratings, such as GDP per capita, exports, inflation, unemployment, exchange rate, total reserves, ratio of trade to GDP and ratio of gross savings to GDP It is discussed. The factors affecting the country credit ratings were examined by panel data analysis on Fragile Eight, which is also included in Turkey. Country credit scores and macroeconomic variable figures between 2000 and 2015 were used in the study.
\end{abstract}

Keywords: Credit Rating Agencies, Fitch, Fragile Eight, Macroeconomic Factors, Panel Data Analysis JEL Codes: C82, C33,G24

ÜLKE KREDI NOTLARINI ETKILEYEN MAKROEKONOMIK FAKTÖRLER: KIRILGAN SEKIZLi ÜZERINE BİR UYGULAMA

\section{ÖZET}

Bu çalışmada, kredi derecelendirme kuruluşları tarafından belirlenen ülke kredi notları ile makroekonomik değişkenler arasındaki ilişki incelenmektedir. Bu kapsamda, çalışmada üç büyük kredi derecelendirme kuruluşundan biri olan Fitch'in derecelendirdiği Kırılgan Sekizli olarak adlandırılan ( Türkiye, Brezilya, Şili, Arjantin, Hindistan, Endonezya, Rusya ve G. Afrika) ülkelerin kredi notları ele alınmıştır. Aynı zamanda, ülke kredi notlarını etkileyen makroekonomik faktörlerden bağımsız değişken olarak Kişi başına GSYiH, ihracat, Enflasyon, İşizlik, Döviz kuru, Toplam Rezervler, Ticaretin GSYiH'ya oranı ve Brüt tasarrufların /GSYiH'ya oranı analizde kullanılırken ülke kredi notları da bağımlı değişken olarak ele alınmışır. Ülke kredi notlarını etkileyen faktörler Türkiye'nin de içinde bulunduğu Kırılgan Sekizli üzerinde panel veri analizi ile incelenmiştir. Çalışmada 2000-2015 yılları arası ülke kredi notları ile makroekonomik değişken rakamları kullanılmıştır. Çalışmanın sonucunda ülke kredi derecelendirme notlarını enflasyon değişkeninin etkilemediği, buna rağmen işsizlik, reel döviz kuru, toplam tasarruf, GSYiH, ihracat ve toplam rezervler ise ülke kredi derecelendirme notlarını etkilediğine dair bulgulara ulaşılmıştır.

Anahtar Kelimeler: Kredi Derecelendirme Kuruluşları, Fitch, Kırılgan Sekizli, Makro Ekonomik Faktörler, Panel Veri Analizi JEL Kodları: C82, C33,G24 


\section{GiRiş}

Finansal piyasaların küreselleşmesi para ve sermaye piyasalarının gelişimine pozitif etki etmektedir. Piyasaların gelişmesiyle beraber, finansal ürünlerin çeşitliliği artmakta ve finansal ürünler karmaşıklaşmaktadır. Bu sebepler, uluslararası sermayenin dolaşım hızında ve hacminde büyük bir artış meydana getirmektedir. Bu durum, fon arz edenlerin istedikleri ülkede, istedikleri alanda yatırım yapmasına olanak tanırken, fon talep edenlerin de kaynaklara ulaşımını kolaylaştırmaktadır. Bununla birlikte, yatırımcılar yatırım yapacakları ülke hakkında yeterince bilgiye sahip olmadıklarında kredi derecelendirme kuruluşlarına ihtiyaç ortaya çıkmıştır.

Ülke kredi notu bir ülkede yatırım ortamının risk düzeyini göstermektedir. Aynı zamanda, ülke kredi notları özel sektör borçlanmasını ve özel sektörün yabancı yatırımcılar açısından çekiciliğini de etkilemektedir. Ülke kredi notu, bir ülkenin finansal sorumluluklarını ne ölçüde gerçekleştirdiği hakkında kredi derecelendirme kuruluşlarının (KDK) açıklamış oldukları görüşleri de ortaya koymaktadır. Yani kredi notu yüksek bir ülkenin uluslararası piyasada borçlanmak için ödemek zorunda olacağı faiz azalmakta, kredi notu düşük ise borçlanmanın maliyeti artmaktadır (Ovalı, 2014:54).

Bu çalışmanın amacı; ülkelerin ve kurumların hem çok önem verdiği hem de çok fazla eleştirdiği aynı zamanda rekabeti artıran, ekonomik krizlerin sinyali olarak kabul edilen ülke kredi notlarının Obelirleyicilerini tespit etmektir. Hangi ekonomik değişkenlerin bu belirleyiciler kapsamına alınıp alınmadığının tespit edilmesi, ülkelere kredi notlarını yükseltmede yol gösterici olmaktadır. Aynı zamanda ülkelerin ekonomi politikalarını bu doğrultuda belirlemeye yönlendirmektedir.

Çalışmada ilk olarak ülke kredi notunun belirleyicilerinin tespitine yönelik literatür taramasına yer verilmiştir. Bir sonraki bölümde teorik beklenti ve ampirik çalışmalar göz önünde bulundurularak, ülke kredi notunun hangi değişkenlerden etkilendiği sorunsalına cevap aranmıştır. Daha sonra veri seti ve yöntemin tanıtılmasının ardından elde edilen bulgular yorumlanmış, son olarak genel bir değerlendirme ile çalışma sonlandırılmıştır.

\section{LITERATÜR INCELEMESI}

Çalışmanın bu bölümünde ülke notlarını açıklamaya yönelik literatürdeki çalışmalar incelenmektedir. Literatürde ülke notlarını açılamaya yönelik kullanılan yöntemler iki farklı şekilde sınıflandırılabilir. Bunlar; nicel bağımlı değişkenli ve nitel bağımlı değişkenli analizlerdir. Literatürde ülke notları ile yapılan çalışmalarda bağımlı değişken kimi çalışmalarda kantitatif belirlenmiş ve lineer analizlerle ülke notları açıklanmaya çalışılmışır. Kimi çalışmalarda ise ülke notlarının niteliksel durumuna vurgu vardır ve ülke notları kalitatif tanımlanmış ve multinominal modeller kullanılmıştır.

Ülkelerin kredi notlarını belirleyen faktörlerle ilgili öncü çalışmalardan bir tanesi Cantor ve Packer'ın (1996) makalesidir. Cantor ve Packer'ın (1996) 49 ülkenin kredi notu inceledikleri çalışmada, kredi notunu etkileyen temel faktörlerin, kişi başına düşen gelir, GSYiH büyümesi, enflasyon, dış borç, ekonomik gelişmişlik düzeyi ve ülkenin temerrüd geçmişi olduğunu tespit etmişlerdir. Afonso (2002)'da çalışmasında benzer sonuçlar bularak yukardaki unsurların ülke riskini ya da kredi notunu etkileyen temel faktörler olduğunu savunmuştur.

Ul-Haque vd. (1996) çalışmalarında 1963 - 1980 dönemi için 60 gelişmekte olan ülkenin kredibilitesi incelemişlerdir. Çalışmada rezervlerin ithalata oranı, ihracat büyüme oranları ve cari denge değişkenleri için anlamlı ve pozitif katsayılar elde edilirken, büyüme oranları ve dış ticaret hadleri için elde edilen katsayılar ise istatistikî bakımdan anlamsız bulunmuştur. Bunun dışında çalışmada ülkelerin kredibilitesi ile ABD faiz oranları arasında negatif ve anlamlı bir ilişkiye ulaşımıştır.

Ferri, Liu ve Stiglitz (1999) yaptıkları araştırma sonucunda kriz dönemlerinde kredi notlarının değiştiğini tespit etmişleridir.

Gür (2000) araştırması sonucunda, ülke notu verilirken politik risk değişkenlerinin dikkate alınmadığını ve bu durumun da not ölçümlerinin sağlıksız olmasına neden olduğunu belirlemiştir.

Kaufmann, Kraay ve Martruzzi (2003) çalışmalarında politik istikrar, yönetim etkinliği, denetim kalitesi, hukukun üstünlüğü ve yolsuzluk kontrolü parametrelerini toplayarak legal yapı endeksi oluşturmuşlardır. Çalışmaları sonucunda ülke notlarını etkileyen en önemli değişkenin legal yapı değişkeni olduğuna karar vermişlerdir.

Canuto, Santos ve Porto (2004) çalışmalarında, düşük seviyede dış borç/cari açığın, yüksek düzeyde kişi başına düşen gelirin, yüksek reel büyüme oranın, düşük enflasyonun ve yerel yönetimlerin toplam borcunun düşük miktarda olmasının yüksek kredi notunun belirleyicileri olduğu sonucuna ulaşmışlardır.

Archer vd. (2007) çalışmasında, 1987 ve 2003 yılları arası üç büyük derecelendirme kuruluşu tarafından verilen ülke notlarını 50 ülke için lineer panel veri analiz vasıtasıyla incelemiştir. Çalışma sonucunda ülkelerin rejim türleri ve diğer politik değişkenlerin ülke kredi notları üzerinde etkilerin çok zayıf olduğunu ve makro ekonomik değişkenlerin ülke notları üzerindeki etkilerinin daha fazla olduğunu belirlemişlerdir.

Iyengar (2010) çalışması sonucunda, kredi notunun belirleyicilerin kişi başına düşen gelir, dış borç, iç borç ve ekonomik kalkınmışlık düzeyi olduğunu tespit etmiştir. 
Kalaycı, Demir ve Gök (2010) çalışmalarında, kredi notunun belirleyicileri olarak Dış Faiz Servisi, Yurt İçi Tasarruflar/GSYiH, Tüketici Fiyatları ve Genel Yönetim Faiz Dışı Bütçe Dengesi/GSYiH değişkenlerini göstermektedir.

Afonso, Gomes ve Rother (2011) çalışmalarında, kısa dönemde kişi başına düşen GSYiH, büyüme hızı, kamu borcu ve bütçe dengesini, uzun dönemde ise güçlü bir devlet, dış borç, yabancı rezervler ve ülkenin temerrüd geçmişini kredi notunun belirleyicisi olarak göstermektedir.

Ratha, Prabak ve Mohapatra (2011) çalışmalarında toplam Rezervler ile ülke notları arasında negatif yönlü ilişki olduğunu, enflasyon oranı ile ülke notları arasında ise anlamlı bir ilişki bulunmadığını ortaya koymuşlardır.

Gültekin-Karakaş, Hisarcıklılar ve Öztürk (2011) çalışmalarında, ülke notları verilirken yüksek gelirli ve düşük gelirli ülke ayrımı yapıldığını belirtmişlerdir. Çalışmaları sonucunda düşük gelirli ülkelerde politik ve sosyal faktörlerin daha çok ön plana çıktığını, yüksek gelirli ülkelerde ise not verilirken daha çok makroekonomik faktörlere dikkat edildiğini tespit etmişlerdir.

Şahinöz ve Gönenç (2011) çalışmaları sonucunda, kurumsal kalite ile para politikasının kredi notu üzerinde oldukça etkili olduğu ve kredi notlarını yükseltmek isteyen gelişmekte olan ülkelerin politik istikrarı sağlamaları, büyümelerini artırmaları ve borçlarını azaltmaları gerektiğini tespit etmişlerdir.

\section{VERI VE YÖNTEM}

Çalışmada kullanılan bağımlı değişkenler için veriler Fitch web sayfalarından temin edilmiştir. Açıklayıcı değişkenler ise Dünya Bankasından elde edilmiştir. Ülkelerin kredi notları Tablo 1.'de belirlenen sayısal sıralama şeklinde ifade edilip, çalışmadaki ekonometrik modelde kullanılmıştır. Makroekonomik değişkenlerin ülke kredi notları üzerindeki etkilerinin araştırıldığı bu çalışmada panel veri ekonometrik teknikleri kullanılmıştır. Analize konu olan her ülke için yıllık kredi notu alınmış, yatay kesit bağımılığı, birim kök testleri uygulanarak panel ikinci nesil analizleri uygulanmıştır. Modelde kullanılan açıklayıcı değişkenler Tablo 2'de ifade edilmiştir.

Çalışmanın uygulama bölümünde derecelendirme kuruluşları tarafından verilen ülke notları sayısal sıralama ile sınıflandırılacaktır. Ardından Kırılgan Sekizli içerisindeki ülkec notlarının seçilmiş ülkelerin makro ekonomik ve politik yapılarından bağımsız hareket edip etmedikleri alternatif ekonometrik modeller vasıtasıyla sınanacaktır. Ekonometrik modeller sonucunda elde edilecek bulgular vasıtasıyla Kırılgan Sekizli ülkelerinde makro ekonomik değişkenlerde olası değişmelerin ülke kredi notları üzerinde etkisi gözlemlenebilecektir. Ayrıca incelenen ülkelerdeki makro ekonomik gelişmeler ülke notlarını beklendiği yönde etkilemesi durumunda, KDK'ların ülke derecelendirme süreçlerinde ülke içi gelişmelerden bağımsız hareket etmedikleri sonucuna ulaşılacaktır. Ülke içi gelişmelerin ülke notları üzerindeki etkilerinin bilinmesinin politikacılar, yurt içi ve yurt dışı yatırımcılar ve akademisyenler için faydalı olacağı düşünülmektedir.

Tablo 1: Kredi Sınıflandırılması

\begin{tabular}{|l|c|c|}
\hline & Kredi Notasyon & Sayısal Sıralama \\
\hline Yatırım Notu Derecelendirmesi & Fitch & \\
\hline En Yüksek Kalite & & \\
\hline Yüksek Kalite & AAA & 21 \\
\hline & AA+ & 20 \\
\hline & AA & 19 \\
\hline Yüksek Ödeme Kapasitesi & AA- & 18 \\
\hline & A+ & 17 \\
\hline & A & 16 \\
\hline Yeterli Ödeme Kapasitesi & A- & 15 \\
\hline & BBB+ & 14 \\
\hline & BBB & 13 \\
\hline & BBB- & 12 \\
\hline Spekülatif Notu Derecelendirmesi & & \\
\hline Yükümlülüklerin yerine getirilme ihtimali & BB+ & 11 \\
\hline
\end{tabular}




\begin{tabular}{|l|c|c|}
\hline Belirsizlik & BB & 10 \\
\hline Yüksek Risk & BB- & 9 \\
\hline & B+ & 8 \\
\hline & B & 7 \\
\hline Yükümlülükler Yerine Getirilemez & B- & 6 \\
\hline & CCC+ & 5 \\
\hline & CCC & 4 \\
\hline & CCC- & 3 \\
\hline & CC & 2 \\
\hline & C & 1 \\
\hline & SD & 0 \\
\hline
\end{tabular}

Tablo 2: Modelde Kullanılan Değişkenler

\begin{tabular}{|l|l|}
\hline Bağımlı Değişken & Bağımsız Değişken \\
\hline Fitch Ülke kredi notu & Kişi Başına GSYiH \\
\hline & İssizlik \\
\hline & ìhracat \\
\hline & Toplam Rezervler \\
\hline & Ticaretin GSYiH'ya oranı \\
\hline & Enflasyon \\
\hline & Döviz Kuru \\
\hline & Brüt tasarrufların /GSYiH'ya oranı \\
\hline
\end{tabular}

\section{BULGULAR VE TARTIŞMA}

Çalışmada, ülke kredi notunu belirleyici makroekonomik değişkenlerin etkisini ölçmek amacıyla kesit ve zaman boyutunu içeren panel veri analizinden yararlanılmıştır. Panel veri setinin heterojenliği engellemesi, çoklu bağlantı sorununa daha az neden olması gibi birçok avantaja sahip olması, ampirik çalışmalarda sıklıkla tercih edilmesinde etkili olmaktadır. Çalışmanın zaman boyutunu 2000-2015 yılları oluştururken, Kırılgan Sekizli olarak adlandırırlan 8 ülke ise birim boyutunu oluşturmaktadır. Çalışmada seçilen makroekonomik değişkenlerin ülke kredi notu üzerindeki etkisini ölçmek için kullanılan panel veri regresyonunda literatürde hakim olan iki temel yaklaşımdan her kesit birimin kendi sabit değeri olan sabit etkiler tercih edilmiştir. (Gujarati ve Porter, 2012:603). Çalışmanın bu bölümünde, seçilen makroekonomik değişkenlerin ve hesaplanan ülke kredi notunun durağanlık seviyesini test etmek amacıyla panel birim kök testleri uygulanmıştır. Birim kök testi sonrasında, nedensellik analizleri ve yatay kesit bağımlılık testleri yapılmış ve ülkelerin kredi notunu hangi makroekonomik değişkenin etkilediği tespit edilmiştir.

\section{Yatay Kesit Bağımlılığı}

Panel veri ekonometrisi ile ilgili analizlerde öncelikle değişkenlerin yatay kesit bağımlılığı içerip içermedikleri incelenmelidir. Panel verilerinde yatay kesit bağımlılığı (cross-section dependence) olduğu halde bu durumun dikkate alınmadan analiz yapılması elde edilecek sonuçları önemli ölçüde etkilemektedir (Breusch and Pagan, 1980; Pesaran, 2004). Bu yüzden en uygun birim kök ve eşbütünleşme testini belirleyebilmek için yatay kesit bağımlılığının sınanması gerekmektedir (Yıldırım vd., 2013: 86). Seriler arasında yatay kesit bağımlıı̆ı yoksa 1. nesil birim kök testleri uygulanmaktadır. Yatay kesit bağımlılığının olduğu serilerde ise 2. Nesil birim kök testlerini kullanmak daha tutarlı, etkin ve güçlü tahminleme yapılmasını sağlamaktadır (Nazlıoğlu, 2010:104; Çınar, 2010: 594).

Panel verilerinde yatay kesit bağımlıı̆̆ının varlığı; Breusch-Pagan (1980) $C_{L M 1}$ testi, Pesaran vd. (2004) $C_{L M 2}$ testi, Pesaran

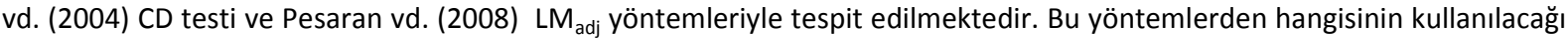


panel verilerinin zaman ve kesit boyutuna göre belirlenmektedir. Kesit boyutu küçük ve zaman boyutu yeterince büyük olduğunda ( $T>N$ ); Berusch-Pagan (1980) $C_{L D_{L M 1}}$ testi, zaman boyutu yatay kesit boyutuna çok yakın veya eşit olduğunda $(T=N)$; Pesaran (2004) $C_{L} D_{L M 2}$ testi, zaman boyutu yatay kesit boyutundan küçük olduğunda $(T<N)$; Pesaran $(2004) C D$ ve

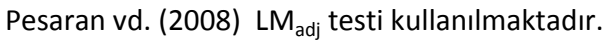

2000-2015 dönemini kapsayan 16 yı (T) ve 8 ülkenin (N) incelendiği bu çalışmada zaman boyutu kesit boyutundan büyük olduğu için $T>N C D_{L M 1}$ ve $C D_{L M 2}$ testlerine göre karar verilecektir. Tablo-3'de ülke gruplarına göre dikkate alınması gereken testin sonuçları italik ve kalın formatta verilmiştir.

CDLM testine ait hipotezler şu şekilde ifade edilebilir:

$H 0:$ ij $=\rho j i=\operatorname{cor}($ uit, ujt) $=0, \quad \mathrm{i} \neq \mathrm{j} \quad$ (Yatay kesitler arasında bağımlılık yoktur)

$H 1: \rho \mathrm{ij}=\rho \mathrm{ji} \neq 0, \quad \mathrm{i} \neq \mathrm{j} \quad$ (Yatay kesitler arasında bağımlılık vardır)

Tablo 3: Yatay Kesit Bağımlılı̆̆ı Testi

\begin{tabular}{|c|c|c|c|c|c|c|c|c|c|c|c|c|c|c|c|c|}
\hline Sabitli Model & Fitch & & InEnf & & Inissiz & & InRdk & & InTsr & & InGSYIH & & Inihr & & InRezerv & \\
\hline & İstatistik & Prob & İstatistik & Prob & İstatistik & Prob & İstatistik & Prob & İstatistik & Prob & İstatistik & Prob & İstatistik & Prob & İstatistik & Prob \\
\hline$C D_{L M 1}(B P, 1980)$ & 170.0267 & 0 & 63.94084 & 0.0001 & 75.46009 & 0 & 117.0014 & 0 & 85.36966 & 0 & 373.8023 & 0 & 429.1133 & 0 & 341.8307 & 0 \\
\hline$C D_{\text {ML2 }}$ (Pesaran, 2004) & 17.91007 & 0 & 3.733752 & 0.0002 & 5.273076 & 0 & 13.73322 & 0 & 6.597298 & 0 & 45.14074 & 0 & 52.53198 & 0 & 40.86835 & 0 \\
\hline$L M_{A D J}(P U Y, 2008)$ & 17.64341 & 0 & 3.467086 & 0.0005 & 5.006409 & 0 & 13.49989 & 0 & 6.330632 & 0 & 44.87407 & 0 & 52.26531 & 0 & 40.60168 & 0 \\
\hline$C D \quad$ (Pesaran, 2004) & 10.81389 & 0 & 2.602038 & 0.0093 & 5.571761 & 0 & 9.604167 & 0 & 0.674276 & 0.5001 & 19.255 & 0 & 20.71356 & 0 & 18.34408 & 0 \\
\hline
\end{tabular}

$\Delta y_{i, t}=d_{i}+\delta_{i} y_{i, t-1}+\sum_{j=1}^{p_{i}} \lambda_{i, j} \Delta y_{i, t-j}+u_{i, t}$ modelinde gecikme sayısı ( $\left.p_{i}\right) 1$ olarak alınmıştır.

Tablo 3'te yer alan sonuçlara göre, tüm ülke gruplarına ait Fitch, enflasyon, işsizlik, reel döviz kuru, toplam tasarruf, GSYiH, ihracat ve toplam rezerv değişkenleri için hesaplanan olasılık değeri 0.05 'ten küçük olduğundan dolayı yatay kesit bağımsızlığını ifade eden sıfır hipotezi reddedilir. Buna göre hem tüm bu seriler için yatay kesit birimleri arasında bağımlılık vardır. Bu sonuçlara göre söz konusu değişkenlerle ilgili olarak ülkelerden birinde meydana gelen bir şok, diğer ülkeleri de etkilemektedir

Panel verilerinde yatay kesit bağımlılığı tespit edildiği için serilerin durağan olup olmadıklarını 2. nesil birim kök testleriyle analiz etmek daha uygun olacaktır. Başlıca ikinci nesil birim kök testleri ise MADF (Multivariate Augmented Dickey-Fuller1998), SURADF (Seemingly Unrelated Regression Augmented Dickey-Fuller-2002), PANKPSS (Carrion-I Silvestre et al. 2005), CADF (Cross-Sectionally Augmented Dickey-Fuller-2006) ve CIPS (Cross-Sectionally Im-Pesaran-Shin-2006)'dır.

Bu bilgiler doğrultusunda birim kök analizi için; CADF (Pesaran, 2006) testinden yararlanılmıştır.

\section{CADF Birim Kök Testi}

CADF ile "panelin genelinde" ve paneli oluşturan serilerdeki her bir "yatay kesit biriminde" birim kök testi yapılabilmektedir. Böylece serilerin durağanlığı hem panelin tamamı hem de her bir ülke için belirlenebilmektedir. Ancak bu çalışmada sadece panelin geneli için serilerin duranlık durumları incelenmiştir. CADF testi mekansal otokorelasyonu dikkate almakta ve her ülkenin zaman etkilerinden farklı etkilendiğini varsaymaktadır. Pesaran yaptığı Monte Carlo simülasyonlarında CADF testinin hem $\mathrm{T}<\mathrm{N}$ hem de $\mathrm{T}>\mathrm{N}$ durumunda geçerli olduğunu ortaya koymuştur (Peseran, 2007: 269, Güloğlu ve İvrendi, 2010: 383). CADF testinde $b_{i}$ katsayılarına ilişkin $\mathrm{t}$ değerleri bulunup Pesaran (2007) kritik değerleriyle karşılaştırılarak serilerin durağanlığı test edilmektedir. Analiz sonucu elde edilen CADF istatistik değeri CADF kritik tablo değerinden küçükse boş hipotez reddedilir. Bu durumda sadece boş hipotezi reddedilen ülkenin serisinin durağan olmadığı sonucuna ulaşıır.

Birim kök hipotezleri aşağıdaki gibi yazılabilir:

$H O: b i=0$ durağandır.

$H 1: b i<0$ durağan değildir. $(\mathrm{i}=1,2, \ldots, \mathrm{N})$ 
Panelin geneli için test istatistiği (CIPS) ve Pesaran (2007) tarafından hesaplanan kritik değerler Tablo-4’te verilmiştir.

Tablo 4: CADF Birim Kök Testi Sonuçları (Panel)

\begin{tabular}{|l|l|l|l|l|l|l|l|l|l|l|l|}
\hline \multicolumn{7}{|l|}{ CADF (CIPS İstatistiği) } \\
\hline \multicolumn{1}{|l|}{ In Initik Tablo } \\
Değerleri
\end{tabular}

Notlar: Maksimum gecikme uzunluğu 4 olarak alınmış ve optimal gecikme uzunlukları, Schwarz bilgi kriterine göre belirlenmiştir.

*, $* *$ ve ${ }^{* * *}$ sırasıyla \%1, \%5 ve \%10 anlamlılık düzeyinde serilerin durağan olduğunu göstermektedir. Test modeli olarak, sabitli ve trendli model seçilmiştir. Kritik değerler, ülke ve zaman boyutu dikkate alınarak sabitli modelde Pesaran (2007) makalesi s. 280 tablo II(b)'den, sabit ve trendli modelde ise Pesaran (2007) makalesi s. 281 Tablo II(c)'den alınmıştır. Panel istatistiği, CADF istatistiklerinin ortalamasıdır.

Tablo-4 incelendiğinde panelin genelini ifade eden CiPS istatistik sonuçları tablo kritik değerinden küçük olduğu için Ho hipotezi kabul edilir. Sabitlide GSYiH ve tasarruflar dışındaki seriler durağan değilken, farklarının alınıması sonucu tüm seriler durağan hale gelmiştir.

Panel veri ekonometrisi ile ilgili eşbütünleşme analizlerinde öncelikle değişkenlerin homojen olup olmadıkları incelenmelidir. Değişkenlerin homojen olup olmamaları, uygulanacak olan eşbütünleşme testlerinin yönünü ve biçimini değiştirmektedir. Bundan dolayı çalışmada eşbütünleşme testinden önce delta testi yardımıyla değişkenlerin homojenliği araştırılmıştır.

Delta testine ait sıfır hipotez ve alternatif hipotezi şu şekilde belirtmek mümkündür:

yit $=$ ai + Bixit+ uit

$H 0: \beta 1=\beta 2=\cdots=\beta n=\beta$ (tüm $\beta i^{\prime}$ ler için)

$H 1: \beta 1=\beta 2=\cdots \neq \beta n$ (en az bir $i$ için)

Tablo 5: Delta Testi Sonuçları

\begin{tabular}{|l|l|l|}
\hline & \multicolumn{2}{|l|}{ Tüm Ülkeler } \\
\hline & Statistic & p-value \\
\hline Homogeneity tests: & & \\
\hline$\tilde{\Delta}$ & 6.12 & 0.00 \\
\hline$\tilde{\Delta}_{\text {ađ̆ }}$ & 6.99 & 0.00 \\
\hline
\end{tabular}

Delta test sonuçlarına göre tüm ülkeler grubunda değişkenlerin homojen olduğu boş hipotezi \%1 anlamlılık düzeyinde reddedilmektedir. Ampirik modelde yer alan değişkenlerin eğim katsayısı heterojendir.

Yatay kesit bağımlılığı ve delta testleri sonuçlarına göre en uygun eşbütünleşme analizi belirlenerek uygulama yapılmıştır. Ayrıca eşbütünleşme analiziyle elde edilen sonuçlardan ilgili kısımlar bu testlere göre seçilerek yorumlanmıştır. 


\section{Panel Eşbütünleşme Testi}

Panel veri analizinde eşbütünleşme hem yatay kesit boyutunda $(N)$ hem de zaman serisi boyutunda $(T)$ bütünleşmiş seriler arasındaki uzun dönemli ilişkinin varlığını test etmektedir (Westerlund, 2007: 709; Mátyás ve Semestre, 2008: 302). Paneli oluşturan serilerin yatay kesit bağımlılı̆̆ı, durağanlığı ve homojenliği araştırıldıktan sonra, elde edilen bilgiler ışığında uygulanacak olan eşbütünleşme testine karar verilmektedir. Çalışmada yatay kesit bağımlığı içeren seriler heterojendir. Bu yüzden çalışmada Westerlund ECM (Error Correction Method) panel eşbütünleşme testi uygulanmıştır.

Panel istatistiklerine ait boş ve alternatif hipotez aşağıdaki gibi ifade edilmektedir:

H0: $a i=0$ bütün yatay kesit birimleri için eşbütünleşme ilişkisi yoktur.

H1: $a i=a<0$ bütün yatay kesit birimleri için eşbütünleşme ilişkisi vardır.

Tablo 6: Westerland (2007) ECM Test Sonuçları

\begin{tabular}{|c|c|c|c|c|}
\hline \multirow{3}{*}{ Tests } & \multicolumn{2}{|l|}{ Constant } & \multicolumn{2}{|c|}{ Constant and Trend } \\
\hline & \multirow{2}{*}{ Statistic } & Bootstrap & \multirow{2}{*}{ Statistic } & Bootstrap \\
\hline & & $p$-value & & $p$-value \\
\hline \multicolumn{5}{|c|}{ Tüm Ülke Grubu } \\
\hline \multicolumn{5}{|c|}{ Error Correction } \\
\hline \multicolumn{5}{|c|}{ (Ho:no cointegration) } \\
\hline Group_tau & -14.674 & 0 & -52.516 & 0 \\
\hline Group_alpha & 2.88 & 0.998 & 4.298 & 0.973 \\
\hline Panel_tau & -11.905 & 0 & -29.855 & 0 \\
\hline Panel_alfa & -0.295 & 0.384 & 1.944 & 0.974 \\
\hline
\end{tabular}

Notlar: Error Correction testinde Gecikme ve öncül bir olarak alınmıştır. Bootstrap olasılık değerleri 1.000 tekrarlı dağılımdan elde edilmiştir. Group-tau ve Group-alpha grup ortalama istatistiklerini, Panel-tau ve Panel-alpha panel istatistiklerini ifade etmektedir. * ${ }^{*}<.01$, $* * \mathrm{p}<.05, * * * \mathrm{p}<.10$ düzeyinde anlamlıdır.

ECM analiz sonuçları yorumlanırken serilerde yatay kesit bağımlılı̆̆ varsa Bootsrap p-value değerleri, yoksa Asymptotic $p$ value değerlerinin dikkate alınması önerilmektedir (Nazlıŏlu, 2010:96). Bu nedenle panel serilerinde yatay kesit bağımlılı̆ı olduğu için ECM testi sonucunda elde edilen Asymptotic p-value değerleri Tablo-6'ya dahil edilmemiştir. Ayrıca seriler heterojense group_tau ve group_alpha, homojense panel_tau ve panel_alfa test istatistiklerine göre analiz sonuçları değerlendirilir. Yukarıda yapılan homejenite testi sonucunda serilerin heterojen olduğu tespit edilmiştir. Dolayısıyla eşbütünleşme testi analiz sonuçlarından group_tau ve group_alpha değerlerine bakılarak sonuçlar değerlendirilmiştir.

ECM test sonuçları, sabitli ile sabitli ve trendli group_tau istatistiklerine göre, HO hipotezinin reddedildiğini göstermektedir. Dolayısıyla Fitch ile diğer değişkenler arasında uzun dönemli bir ilişki olduğu ortaya çıkmıştır.

\section{Asimetrik Panel Nedensellik Testi}

Panelin geneline ait Granger nedensellik test sonuçları Tablo 7'te raporlanmaktadır. Test edilen hipotezler "enflasyon, işsizlik, reel döviz kuru, toplam tasarruf, GSYiH, ihracat ve toplam rezervlerde meydana gelen büyüme Fitch'in ülkelere vermiş olduğu kredi notlarının Granger nedeni değildir" şeklindedir. 


\begin{tabular}{|ll|r|r|}
\hline \multicolumn{4}{|c|}{ Tablo-7: Panel Nedensellik Test Sonuçları } \\
\hline Nedenselliğin Yönü & MWALD & Olasılık \\
\hline GSYIH & Fitch & 60.87 & 0 \\
\hline Enflasyon & Fitch & 9.172 & 0.906 \\
\hline İhracat & Fitch & 31.96 & 0.01 \\
\hline İşsizlik & Fitch & 26.964 & 0.042 \\
\hline Döviz K. Fitch & Fitch & 36.336 & 0.003 \\
\hline T. Rezerv & Fitch & 50.828 & 0 \\
\hline Tasarruflar
\end{tabular}

Not: \#> notasyonu nedenselliğin olmadığı sıfır hipotezini göstermektedir.

Tablo 7'de yer alan bilgilere göre Ho hipotezi enflasyon dışındaki tüm değişkenler için reddedilmiştir. Yani işsizlik, reel döviz kuru, toplam tasarruf, GSYiH, ihracat ve toplam rezervler ülke kredi derecelendirme notlarının nedenidir. Dolayısıyla Fitch'in ülkeleri notlandırma sürecine, işsizlik, reel döviz kuru, toplam tasarruf, GSYiH, ihracat ve toplam rezervler etki etmektedir.

\section{SONUÇ}

Fitch Kredi Derecelendirme Kuruluşu tarafından açıklanan ülke kredi notlarının Türkiye'nin de içinde bulunduğu Kırılan Sekizli olarak adlandırılan ülkeler açısından analiz edildiği çalışmada elde edilen sonuçlar şu şekilde özetlenebilir. İlk olarak çalışmanın ampirik kısmında ülke kredi notunun belirleyicileri olarak ele alınana makro ekonomik faktörler literatüre ve teoriye uygun değişkenler arasından tercih edilmiştir. Yapılan panel veri analizi sonuçları gösteriyor ki, seçilen sekiz makro ekonomik faktörden enflasyonun ülke kredi notuna etkisi anlamsızdır. Diğer makro ekonomik faktörlerin ise ülke kredi derecelendirme notlarında anlamlı sonuçlara yol açtığı tespit edilmiştir.

\section{KAYNAKLAR}

Afşar, a., \& Karaçayır, E. (2016). Ülke Kredi Notunun Belirleyicileri Türkiye ve AB Ülkeleri Üzerine Bir Uygulama. Journal Of Economics, Finance and Accounting, 3(4), 320-329.

Afonso, A. (2002), "Understanding The Determinants of Government Debt Ratings: Evidence forhe the Two Leading Agencies", Department of Economics and Research Center on the Portuguese Economy (CISEP), Lisbon.

Archer, C. C., Biglaiser, G., ve DeRouen, K. Jr. (2007), "Sovereign Bonds and the Democratic Advantage: Does Regime Type Affect Credit Rating Agency Ratings in the Developing World?" [Ülke Bonoları ve Demokratik Avantaj: Gelişen Dünyada Rejim Türleri Kredi Derecelendirme Kuruluşlarının Derecelendirmesini Etkiler mi?] International Organization, Vol.61, No.2 (Spring 2007), pp. $341-365$

Breusch, T.S. ve Pagan, A.R. (1980), "The Lagrange Multiplier Test and Its Applications to Model Spesification in Econometrics", The Review of Economic Studies, 47(1), 239-253.

Cantor, R. ve Packer, F. (1996), "Determinants and Impact of Sovereign Credit Rating". [Ülke Kredi Notlarının Etkileri ve Belirleyicileri]. Federal Reserve Bank of New York Economic Policy Review, pp:37-54.

Çınar, Serkan. (2010), OECD Ülkelerinde Kişi Başına GSYiH Durağan mı? Panel Veri Analizi, Marmara Üniversitesi i.i..B.F. Dergisi 29(2), 591601

Gültekin-Karakaş, D., Hisarcıklılar, M. ve Öztürk, H., (2011), “Sovereign Risk Ratings: Biased Toward Developed Countries?”, Emerging Markets Finance \& Trade, 47(2), 69-87.

Gür, T. (2000), “Ülke Riskinin Belirlenmesinde Yöntemler”, H.Ü. İktisadi ve İdari Bilimler Dergisi, 18(2): 119-139.

Gür, T. H. \& Öztürk, H. 2011, “Ülke Riski, Derecelendirme Kuruluşları, Aksaklıklar ve Yeni Düzenlemeler" Sosyoekonomi Dergisi. 20112/110204, pp. 69-92

Ferri, G., Liu, L. ve Stiglitz, J.E. (1999). "The Procyclical Role of Rating Agencies: Evidence from The East Asian Crisis". [Derecelendirme Kuruluşlarının Döngüsel Rolü: Doğu Asya Krizinden Deliller]. Economic Notes 28, 335-355 
Kaufmann, D., Kraay, A. ve Mastruzzi, M. (2003). “Governance Matters 3: Governance Indicators for 1996-2002”. [Yönetim Meseleleri 3: 1996-2002 arası Yönetim Endeksi]. Word Bank Working Paper, No:3106

Iyengar, S. (2010), “Are Sovereign Credit Ratings Objective and Transparent?”, The IUP Journal of Financial Economics, Vol. VIII, No.3.

Matyas, L. ve Sevestre, P. (2008), The Econometrics of Panel Data Fundamentals and Recent Developments in Theory and Practice, Third Edition, Germany: Springer.

Nazlıoğlu, Şaban, (2010) Makro İktisat Politikalarının Tarım Sektörü Üzerindeki Etkisi: Gelişmiş ve Gelişmekte Olan Ülkeler İçin Bir Karşılaştırma, Erciyes Üniversitesi, Sosyal Bilimler Enstitüsü, (Yayımlanmamış Doktora Tezi).

Ratha, D., Prabak, K., De ve Mohapatra, S. (2010). "Shadow Sovereign Rating for Unrated Developing Countries". [Derecelendirilmemiş Gelişmekte Olan Ülkeler İçin Gölge Ülke Notları]. World Development, Volume 39, Issue 3, March 2011, Pages 295-307

Pesaran, M.H. (2004), "General Diagnostic Tests for Cross Section Dependence in Panels", Cesifo Working Paper, No: $1229,1-40$.

Pesaran, M.H. (2007), "A Simple Panel Unit Root Test in the Presence of Cross-Section Dependence", Journal of Applied Econometrics, 22(2), 265-312.

Pesaran, M. H., Ullah, A. ve Yamagata, T. (2008), “A Bias-Adjusted LM Test of Error Cross-Section Independence”, Econometrics Journal, 11, 105-127.

Ovalı, S. 2014. "Ülke Kredi Notu Değerlendirme Kriterleri Açısından Türkiye: Ab İle Karşılaştırmalı Analiz" Uluslararası Yönetim iktisat ve işletme Dergisi, Cilt 10, Sayı 23, pp. 53-81.

Şahinöz, S. ve Gönenç, R. (2011), "Determinants of Credit Ratings, Sovereign Bond Spreads and Real Interest Rates In Emerging Markets", İktisat İşletme ve Finans, 26(305), 9-35.

Ul-Haque, N., Kumar, M.S., Mark, N. ve Mathieson, D.J., (1996). "The economic content of indicators of developing country creditworthiness", [Gelişmekte Olan Ülkelerin Kredibilitesinin Göstergelerinin Ekonomik İçeriği]. International Monetary Fund Staff Papers, $43,688-724$.

Yıldırım, K., Mercan, M., Kostakoğlu, S. F. (2013), Satın Alma Gücü Paritesinin Geçerliliğinin Test Edilmesi: Zaman Serisi ve Panel Veri Analizi, Eskişehir Osmangazi Üniversitesi İ.i..B.F. Dergisi, 8(3), 75- 95

Westerlund, J. (2007), "Testing for Error Correction in Panel Data", Oxford Bulletin of Economics and Statistics, 69(6), 709-748. 